\title{
Intracoronary Trimetazidine Does Not Improve Recovery of Regional Function in a Porcine Model of Repeated Ischemia
}

\author{
M.M.G. Koning, ${ }^{1}$ R. Krams, ${ }^{1}$ C.S. Xiao, ${ }^{1}$ \\ J.R. van Meegen, ${ }^{1}$ K. Bezstarosti, ${ }^{2}$ \\ J.M.J. Lamers, ${ }^{2}$ and P.D. Verdouw ${ }^{1}$ \\ ${ }^{1}$ Experimental Cardiology, Thoraxcenter and ${ }^{2}$ Department \\ of Biochemistry, Cardiovascular Research Institute COEUR, \\ Erasmus University Rotterdam, Rotterdam, The Netherlands
}

Summary. We evaluated the effect of trimetazidine (TMZ) on recovery of regional cardiac function in anesthetized open-chest pigs, subjected to fifteen 2-minute occlusions of the left anterior descending coronary artery, separated by 2 minutes of reperfusion and a 120 -minute recovery period. Regional myocardial function was evaluated by sonomicrometry-derived segment lengthening and the area enclosed by the left ventricular pressure-segment length loop (external work, EW) in animals, which received either an intracoronary infusion of TMZ $(33 \mu \mathrm{g} / \mathrm{kg} / \mathrm{min}, \mathrm{n}=6)$ or saline $(1 \mathrm{ml} /$ min, $n=7$ ), starting 15 minutes before the first occlusion and ending 2 minutes after the 15th occlusion. In addition, myocardial malondialdehyde production to evaluate oxygen free radical production, oxygen consumption, and the ATP, ADP, and AMP content, as well as the energy charge, were determined at regular time intervals.

In control pigs the sequences of occlusion-reperfusion did not affect systemic hemodynamics, except for the LVdP/ $\mathrm{dt}_{\max }$, which decreased by $11 \%$ during the interventions and did not recover during the following reperfusion period of 2 hours $(78 \%$ of baseline, $\mathrm{p}<0.05)$. Systolic segment length shortening and $\mathrm{EW}$ were increased at the end of the first occlusion-reperfusion cycle, decreased gradually during the remainder of the occlusion-reperfusion periods, and did not improve during the recovery period. Energy charge and myocardial blood flow were not impaired, but oxygen consumption was decreased during the recovery period. The malondialdeyde data did not provide evidence for production of oxygen free radicals. TMZ decreased $\mathrm{LVdP} / \mathrm{dt}_{\max }$ by $6 \%$ (p $<$ 0.05 ) and caused a twofold increase in postsystolic segment shortening $(p<0.05)$ before the first occlusion, but did not influence the hemodynamic responses, the changes in regional cardiac function, and the metabolic events produced by repetitive regional ischemia.

Cardiovasc Drugs Ther 1993;7:801-807

Key Words. trimetazidine, myocardial ischemia, reperfusion, regional myocardial perfusion and function, external work, oxygen free radicals, high energy phosphates

The effectiveness of the 1-(2,3,4-trimethoxybenzyl)piperazine dihydrochloride, trimetazidine, in increasing the ischemic threshold during exercise tolerance testing without obvious changes in hemodynamic parameters has led to further investigations concerning the mechanisms by which the drug exerts its action [1-3]. A number of properties, mainly demonstrated in isolated organs and tissues, have been identified that could explain the cardioprotective activity of trimetazidine: (a) reduced intracellular acidosis during ischemia $[4,5]$, (b) accelerated adenine nucleotide rephosphorylation $[4,6]$, (c) decreased membrane content of peroxidized lipids [7], and (d) diminished cellular edema and preservation of oxidative phosphorylation during reperfusion. The latter two arguments indicate a reduction in oxygen free radical production [8].

Kober et al. [9] demonstrated recently that intracoronary administration of trimetazidine delayed the development and reduced the magnitude of ECG changes in patients undergoing percutaneous transluminal coronary angioplasty (PTCA) during balloon inflation. In this study it was not investigated whether this was also accompanied by an improved recovery of regional cardiac function after reperfusion was reinstated. Several studies suggest that, in particular, the diastolic function shows an impaired recovery after repeated brief (2-4 minute) coronary artery occlusions $[10,11]$.

In the present study we, therefore, investigated the effects of trimetazidine on the recovery of regional cardiac function after multiple 2-minute occlusions separated by 2 minutes of reperfusion, mimicking a clinical PTCA protocol. Since other studies $[7,8]$ have indicated that trimetazidine or its metabolite(s) may reduce the formation of oxygen free radicals, a potential mechanism for myocardial stunning [12], we also

Address for correspondence: P.D. Verdouw, PhD, Experimental Cardiology, Thoraxcenter, Erasmus University Rotterdam, P.O. Box 1738, 3000 DR Rotterdam, The Netherlands.

Received \& March 1993, accepted in revised form 19 May 1993. 
determined myocardial malondialdehyde (MDA) production to investigate whether the formation of oxygen free radicals plays a role in this model.

\section{Methods}

\section{Surgical procedure}

After an overnight fast, crossbred Landrace $\times$ Yorkshire pigs of either sex (25-32 kg) were sedated with $25 \mathrm{mg} / \mathrm{kg}$ ketamine (A.U.V., Cuijck, The Netherlands) i.m., anesthetized with $18 \mathrm{mg} / \mathrm{kg}$ pentobarbital (Sanofi, Paris, France) i.v., intubated, and connected to a respirator for intermittent positive pressure ventilation with a mixture of oxygen and nitrogen. By adjusting respiratory rate, tidal volume, and the fraction of oxygen in the inspired mixture, arterial blood gases and $\mathrm{pH}$ were kept within the normal limits. The temperature of the animal was kept around $37^{\circ} \mathrm{C}$ by using an electrical blanket. Anesthesia was maintained with a continuous infusion of pentobarbital $(10-15 \mathrm{mg} / \mathrm{kg} / \mathrm{h}$, i.v.). Saline and haemaccel (Behringwerke A.G., Marburg, Germany) were infused to maintain the fluid balance via catheters inserted into the external jugular vein. Catheters were also positioned via both femoral arteries into the descending aorta for measurement of central aortic blood pressure and withdrawal of blood samples for determination of blood gases and malondialdehyde concentrations. A $7 F$ Sensodyn microtransducer catheter (B. Braun Medical B.V., Uden, The Netherlands) was advanced into the left ventricle (LV) via the carotid artery to monitor left ventricular pressure and its first derivative $(\mathrm{LVdP} / \mathrm{dt})$. Following administration of 4 $\mathrm{mg}$ pancuronium bromide (Organon Teknika B.V., Boxtel, The Netherlands) i.v., a midline thoracotomy was performed, the left mammary vessels were ligated, and the second and third left ribs were partly removed to facilitate additional instrumentation. An electromagnetic flow probe (Skalar, Delft, The Netherlands) was placed around the ascending aorta and the left atrial appendage was cannulated for injection of $1-2 \times 10^{6}$ microspheres, $15 \pm 1$ (SD) $\mu \mathrm{m}$ in diameter (NEN Company, Dreieich, Germany), labelled with either ${ }^{95} \mathrm{NB},{ }^{103} \mathrm{Ru},{ }^{113} \mathrm{Sn},{ }^{46} \mathrm{Sc}$, or ${ }^{141} \mathrm{Ce}$, to determine regional myocardial blood flow using the reference blood sample technique. For the measurement of regional segment shortening by sonomicrometry (Triton Technology, San Diego, CA) ultrasonic crystals (Sonotek Corporation, Del Mar, CA) were positioned in the layers of the left ventricle subendocardium, covering the interventional area as well as a control area. The proximal left anterior descending coronary artery (LADCA) was dissected free to apply intermittent occlusions with an atraumatic clamp and a proximally placed electromagnetic flow probe. Distal to this site a small cannula ( $0.8 \mathrm{~mm}$ outer diameter) was inserted into the LADCA for the administration of either trimetazidine or saline. The vein accompanying the
LADCA was cannulated for the determination of coronary venous blood gases, malondialdehyde, and hemoglobin concentrations. At the end of the experiment the interventional area was identified by an intraatrial injection of methylene blue after the LADCA had been occluded again. The pigs were then sacrificed with an overdose of pentobarbital, and the heart was excised and processed to determine regional myocardial blood flow.

\section{Experimental procedure and data analysis}

After surgical preparation the pigs were allowed to stabilize for 45 minutes. Prior to the intervention protocol, which consisted of 15 sequences of 2-minute occlusion and 2 minutes reperfusion, pigs either received an intracoronary infusion of saline or trimetazidine $(33 \mu \mathrm{g} / \mathrm{kg} / \mathrm{min})$ at a rate of $1 \mathrm{ml} / \mathrm{min}$, which started 15 minutes before the first occlusion and continued until the end of reperfusion 15 (at 2 minutes of the final reperfusion period), which was then followed by 2 hours of recovery. At scheduled intervals recordings were made of systemic hemodynamic variables and regional myocardial function, arterial and coronary venous blood samples were drawn to quantify oxygen consumption and malondialdehyde production, biopsies were taken for the determination of highenergy phosphates, and microspheres were injected to obtain regional blood flow data.

From the segment length tracings were calculated (Figure 1) (a) regional systolic segment shortening as $\mathrm{SS}(\%)=100 \times(\mathrm{EDL}-\mathrm{ESL}) / \mathrm{EDL}$, in which $\mathrm{EDL}$ and ESL are the segment length at end diastole and end systole, respectively; (b) regional postsystolic segment shortening (PSS) as PSS $(\%)=100(\%) \times$ (ESL - minL)/EDL, in which minL is the segment length at maximal contraction; (c) normalized regional velocity of contraction $\left(V_{C}\right)$ as $V_{C}(\mathrm{~mm} / \mathrm{s})=10(\mathrm{~mm})$ (EDL-ESL/EDL) $/ t_{\text {systole }}$, in which $t_{\text {systole }}$ equals the $d u-$ ration of left ventricular ejection; and (d) the relaxation time $\left(\mathrm{t}_{50}\right)$ as the duration of the period (ms) in which $50 \%$ of total segment lengthening was achieved. Left ventricular pressure and myocardial segment length were digitized (sample rate $250 \mathrm{~Hz}$ ) using an 8-bit AD converter (Tiepie Engineering, Leeuwarden, The Netherlands) on an IBM PC computer to calculate the area enclosed by the pressure-segment length loop over a full cardiac cycle [13], which is an index of regional myocardial work [14].

High-energy phosphates were measured in transmural myocardial biopsies, taken with a Tru-Cut needle (Travenol Laboratories, Deerfield, IL) from the intermittent ischemic area and the adjacent control area. Biopsies were immediately dipped into $0.9 \%$ $\mathrm{NaCl}$ at $0^{\circ} \mathrm{C}$ to remove adherent blood, frozen in liquid nitrogen (within 10 seconds), and stored until analysis at $-80^{\circ} \mathrm{C}[15]$.

MDA formation was measured in blood samples that were placed on ice directly after sampling, centrifuged at $0^{\circ} \mathrm{C}$ to obtain plasma, and stored at $-80^{\circ} \mathrm{C}$ 


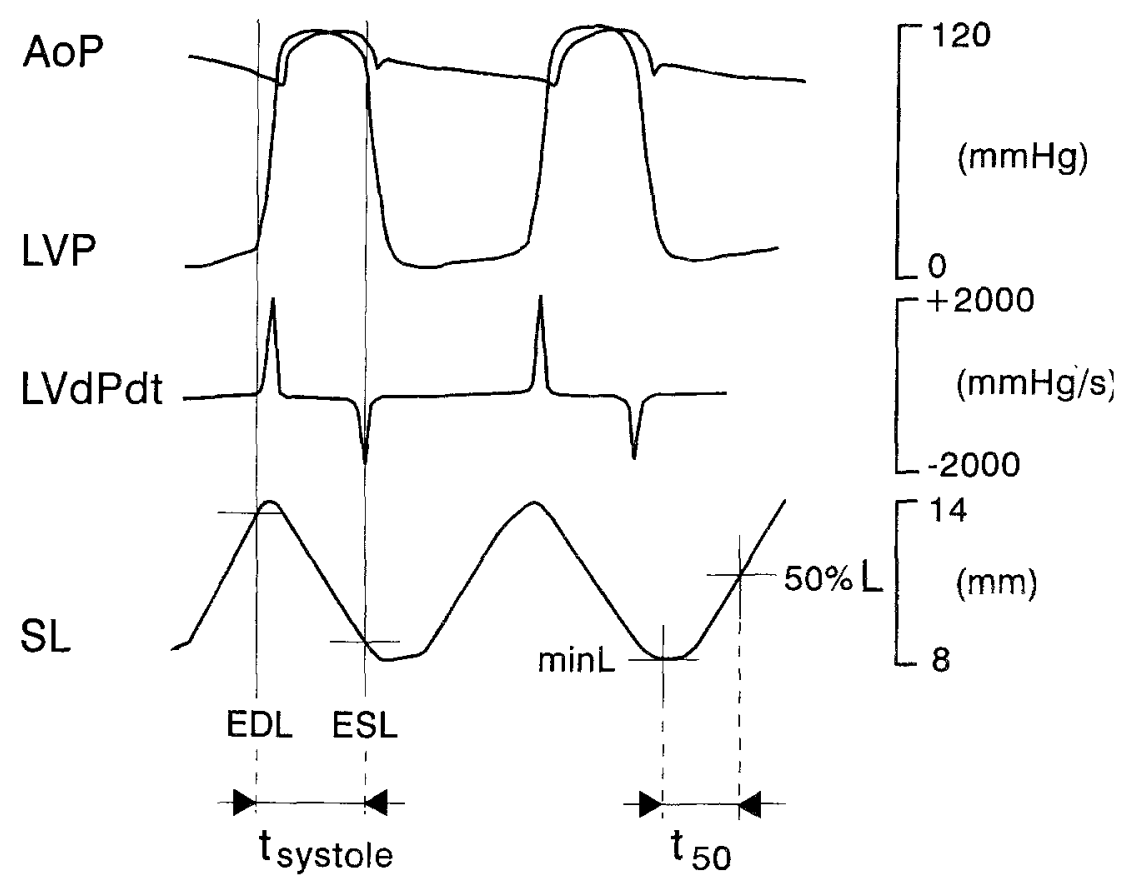

Fig. 1. Calculation of regional segment function data from the segment length tracings. AoP $=$ aortic pressure; LVP $=$ left ventricular pressure; LVdPdt $\times$ first derivative of $L V P ; S L=$ segment length; EDL = end-diastolic length; ESL $=$ end-systolic length; $\min L=$ minimum length (at maximal contraction); $50 \% L=$ length at $50 \%$ relaxation; $t_{\text {systole }}=$ duration of left ventricular ejection; $t_{50}=$ time-period in which $50 \%$ of the relaxation is achieved.

until analysis. The MDA content of the plasma samples was measured as previously described [16].

Oxygen consumption $\left(\mathrm{MVO}_{2}\right)$ and $\mathrm{MDA}$ production were calculated as the product of regional transmural myocardial blood flow and the difference in the arterial and coronary venous contents. Energy charge was calculated as (ATP + $0.5 \mathrm{ADP}) /[\mathrm{ATP}+\mathrm{ADP}+$ AMP] as defined by Atkinson [17].

\section{Statistical analysis}

All data are presented as mean \pm SEM. Statistical analysis was performed by use of a parametric twoway analysis of variance (randomized block design), followed by the Duncan new multiple range test. Statistical significance was accepted at $p<0.05$ (twotailed).

\section{Drugs}

Except for the anesthetic drugs, only trimetazidine (courtesy of Dr. C. Harpey, I.R.I.S., Courbevoie, France) dissolved in isotonic saline was used.

\section{Results}

\section{Systemic hemodynamics}

Two minutes after the last occlusion, $\mathrm{LVdP} / \mathrm{dt}_{\max }$ had decreased to 85-90\% of the preocclusion value, but none of the other cardiovascular variables were significantly affected (Table 1). During the following 15 minutes, there was an additional decrease in LVdP/ $\mathrm{dt}_{\max }$ to $80 \%$ of its preocclusion value $(\mathrm{p}<0.05)$, not followed by any sign of recovery. Hence, at the end of the recovery period, the values of all variables except for that of $\mathrm{LVdP} / \mathrm{dt}_{\max }$ were similar to those observed before the first occlusion.

Infusion of trimetazidine did not alter heart rate, mean arterial blood pressure, cardiac output, and left ventricular end-diastolic pressure, but decreased $\mathrm{LVdP} / \mathrm{dt}_{\max }$ by $6 \%(\mathrm{p}<0.05)$. The drug did not modify the changes in the hemodynamic variables during the occlusion-reperfusion protocol. During the recovery period, in contrast with the untreated animals, there was a complete recovery of $\mathrm{LVdP} / \mathrm{dt}_{\text {rnax }}$ in the trimetazidine-treated animals (Table 1 ).

\section{Regional myocardial wall function}

In the untreated animals, the first occlusion caused a complete loss of systolic segment shortening (SS) of the myocardium perfused by the LADCA, but there was a complete recovery during reperfusion (Figure 2). As a matter of fact SS was even slightly increased to above baseline. During the subsequent occlusionreperfusion cycles there was again a complete loss of function during occlusion, while recovery became only partial during reperfusion. Consequently, 2 minutes after the 15 th occlusion SS had decreased from $18 \pm$ $2 \%$ at baseline to $13 \pm 2 \%(p<0.05)$ and further declined to $9 \pm 1 \%(p<0.05)$ during the following 15 minutes. There were no further changes in SS during the remainder of the reperfusion period. Postsystolic 
Table 1. Systemic hemodynamic effects induced by 15 consecutive cycles of 2 minutes occhusion and 2 minutes reperfusion in untreated $(C, n=7)$ and trimetazidine-treated (TMZ, $n=6$ ) open-chest anesthetized pigs

\begin{tabular}{|c|c|c|c|c|c|c|c|}
\hline & & \multirow[b]{2}{*}{ Pretrimetazidine } & \multirow[b]{2}{*}{ Preocclusion } & \multicolumn{4}{|c|}{ Recovery after last occlusion (minutes) } \\
\hline & & & & 2 & 15 & 60 & 120 \\
\hline \multirow[t]{2}{*}{ HR } & $\mathrm{C}$ & $111 \pm 7$ & $112 \pm 7$ & $109 \pm 5$ & $108 \pm 6$ & $108 \pm 7$ & $111 \pm 8$ \\
\hline & TMZ & $105 \pm 7$ & $104 \pm 8$ & $106 \pm 6$ & $106 \pm 5$ & $108 \pm 5$ & $104 \pm 6$ \\
\hline \multirow[t]{2}{*}{ MAP } & $\mathrm{C}$ & $97 \pm 4$ & $98 \pm 3$ & $94 \pm 5$ & $93 \pm 6$ & $91 \pm 2$ & $98 \pm 6$ \\
\hline & TMZ & $91 \pm 3$ & $92 \pm 3$ & $85 \pm 2$ & $84 \pm 2^{b}$ & $82 \pm 2^{a, b}$ & $83 \pm 5$ \\
\hline \multirow[t]{2}{*}{$\mathrm{LVdP} / \mathrm{dt}_{\max }$} & $\mathrm{C}$ & $2180 \pm 190$ & $2360 \pm 160$ & $2070 \pm 110$ & $1850 \pm 170^{\mathrm{a}}$ & $1840 \pm 180^{a}$ & $1890 \pm 210^{\mathrm{a}}$ \\
\hline & TMZ & $2250 \pm 250$ & $2090 \pm 210^{\mathrm{a}}$ & $1950 \pm 210$ & $1880 \pm 230^{\mathrm{a}}$ & $2000 \pm 310$ & $2480 \pm 300$ \\
\hline \multirow[t]{2}{*}{ LVEDP } & $\mathrm{C}$ & $14 \pm 1$ & $14 \pm 1$ & $14 \pm 1$ & $14 \pm 1$ & $13 \pm 1$ & $13 \pm 1$ \\
\hline & TMZ & $12 \pm 2$ & $13 \pm 2$ & $14 \pm 2$ & $14 \pm 2$ & $14 \pm 2$ & $12=2$ \\
\hline \multirow[t]{2}{*}{$\mathrm{CO}$} & $\mathrm{C}$ & $2.6 \pm 0.3$ & $2.6 \pm 0.2$ & $2.5 \pm 0.2$ & $2.5 \pm 0.2$ & $2.4 \pm 0.3$ & $2.3 \pm 0.2$ \\
\hline & TMZ & $2.3 \pm 0.2$ & $2.5 \pm 0.3$ & $2.5 \pm 0.2$ & $2.5 \pm 0.2$ & $2.4 \pm 0.2$ & $2.2 \pm 0.3$ \\
\hline \multirow[t]{2}{*}{ SVR } & $\mathrm{C}$ & $40 \pm 3$ & $40 \pm 4$ & $39 \pm 3$ & $38 \pm 3$ & $44 \pm 5$ & $46 \pm 6$ \\
\hline & TMZ & $40 \pm 3$ & $38 \pm 4$ & $35 \pm 2$ & $34 \pm 2$ & $36 \pm 3$ & $39 \pm 4$ \\
\hline
\end{tabular}

Trimetazidine infusion $(33 \mu \mathrm{g} / \mathrm{kg} / \mathrm{min})$ started 15 minutes prior to the first occlusion and lasted until 2 minutes after the last occlusion. $\mathrm{HR}=$ heart rate (beats $/ \mathrm{min}) ; \mathrm{MAP}=$ mean arterial blood pressure $(\mathrm{mmHg}) ; \mathrm{LVdP} / \mathrm{dt}_{\max }=$ maximal rate of rise of left ventricular pressure $(\mathrm{mmHg} / \mathrm{s}) ; \mathrm{LVEDP}=$ left ventricular end-diastolic pressure $(\mathrm{mmHg}) ; \mathrm{CO}=$ cardiac output $(\mathrm{l} / \mathrm{min})$; $\mathrm{SVR}=$ systemic vascular resistance $(\mathrm{mmHg} / \mathrm{min} / 1)$.

Data have been expressed as mean \pm SEM.

${ }^{\mathrm{a}} \mathrm{p}<0.05$ versus baseline; ${ }^{\mathrm{b}} \mathrm{p}<0.05$ versus trimetazidine.

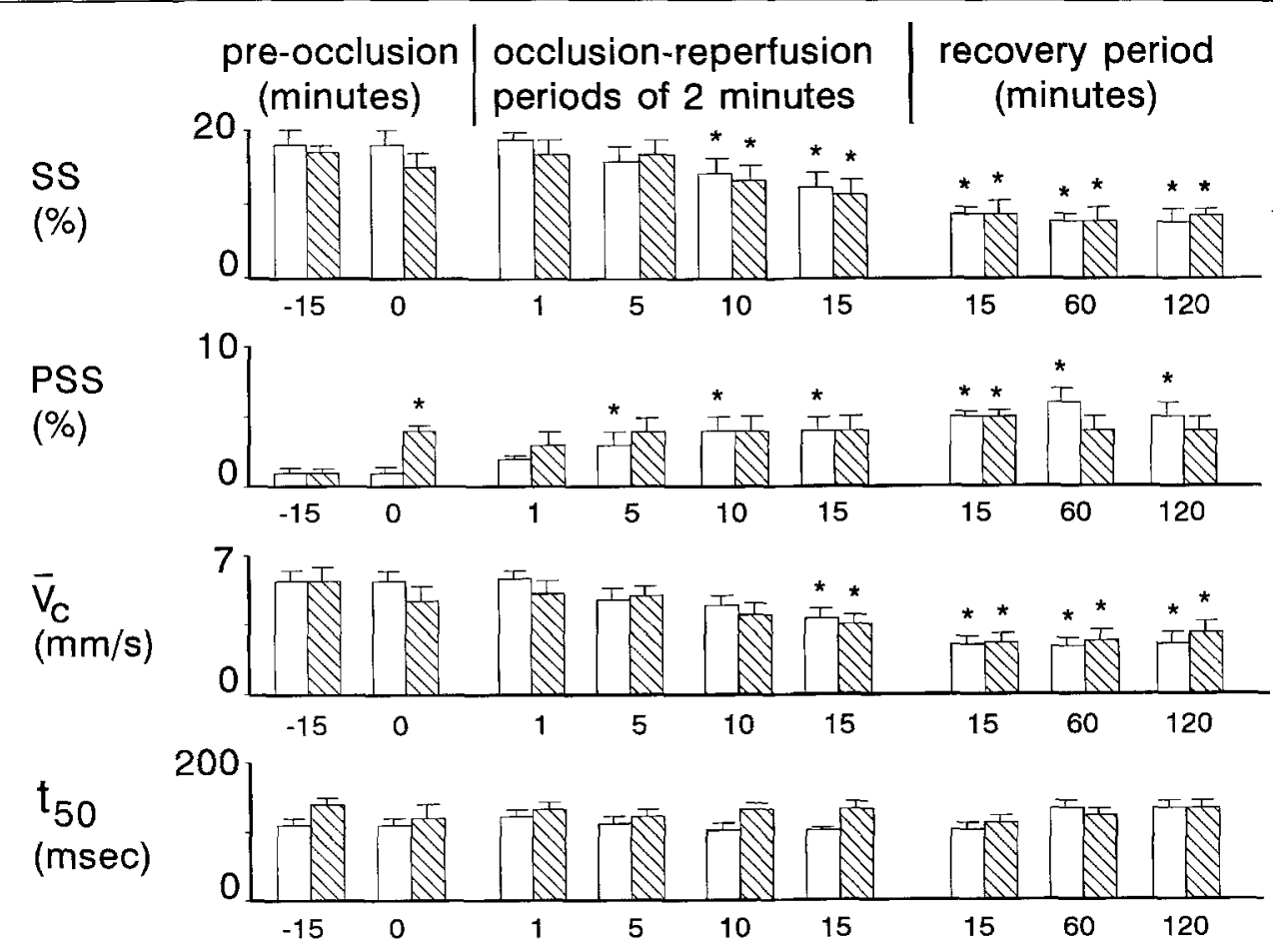

Fig. 2. Effect of 15 consecutive occlusion-reperfusion periods of 2 minutes each in untreated (open columns, $n=7$ ) and trimetazidine-treated (hatched columns, $n=6$ ) animals on segment length changes (SS), postsystolic segment length changes (PSS), velocity of contraction $\left(V_{C}\right)$, and relaxation time $\left(t_{50}\right)$. Data are shown from 15 and 0 minutes before the first occlusion and from the end of the 1st (1), 5th (5), 10th (10), and 15th (15) occlusion-reperfusion periods and from 15 (15), 60 (60), and 120 minutes of reperfusion during the recovery period. Trimetazidine was administrated before and during the occlusion-reperfusion periods. ${ }^{*} p<0.05$ versus minus 15 minutes ( -15 ) before the first occlusion. Data are presented as mean \pm standard error of the mean. 
shortening (PSS) was absent at baseline and also after the first occlusion-reperfusion sequence, but gradually increased during the following occlusion-reperfusion sequences ( $4 \pm 1 \%$ after the 15 th sequence). There were no further changes in PSS during the recovery period. The changes in the velocity of systolic shortening were parallel to those in SS, because heart rate and the duration of systole did not change. The relaxation time was not affected by the first occlusionreperfusion sequence, but gradually shortened during the following sequences, to be prolonged again during the 120-minute recovery period. In the adjacent control region SS decreased from $17 \pm 1 \%$ at baseline to $13 \pm 1 \% 2$ minutes after the last occlusion period and did not change during the ensuing recovery period of 120 minutes. PSS never became significantly different from zero, and the changes in the velocity of shortening again paralleled those in SS, while relaxation time was not affected.

Intracoronary infusion of trimetazidine had no significant effect on SS, neither before and during the occlusion-reperfusion periods, nor during the 120 minute recovery period (Figure 2). The same was true for velocity of shortening and the relaxation time. PSS, however, increased from $1 \pm 0.3 \%$ to $4 \pm 0.4 \%$ $(p<0.05)$, which was neither enhanced by the repetitive occlusions nor attenuated during the recovery period.

\section{External work}

In the untreated animals, the index reflecting the external work performed by the myocardium perfused by the LADCA ( $231 \pm 31 \mathrm{mmHg} / \mathrm{mm}$ at baseline) decreased to virtually zero during the occlusions, but was unchanged at the end of the 1st, 5th, 10th, and 15 th reperfusions. During the following 120 -minute recovery period there was a decline to $151 \pm 18$ $\mathrm{mmHg} / \mathrm{mm}(\mathrm{p}<0.05)$ after 15 minutes, which did not improve during the remainder of the observation period $(140 \pm 16 \mathrm{mmHg} / \mathrm{mm}$ after 120 minutes).

Trimetazidine administration tended to decrease external work in the intervention region $(231 \pm 33$ $\mathrm{mmHg} / \mathrm{mm}$ at baseline and $217 \pm 8 \mathrm{mmHg} / \mathrm{mm}$ after 10 -minute intracoronary infusion, $p=0.16$ ). During the following occlusion-reperfusion sequences, the changes in the trimetazidine animals resembled closely those in the untreated animals $(199 \pm 38$ $\mathrm{mmHg} / \mathrm{mm}$ after the last occlusion-reperfusion cycle and $178 \pm 36 \mathrm{mmHg} / \mathrm{mm}$ after 120 minutes of recovery).

\footnotetext{
Myocardial blood fow

Baseline values of the untreated animals and the trimetazidine-treated animals of the myocardium perfused by the LADCA were very similar $(158 \pm 13 \mathrm{ml} /$ $\mathrm{min} / 100 \mathrm{~g}$ and $160 \pm 18 \mathrm{ml} / \mathrm{min} / 100 \mathrm{~g}$, respectively). In either group of animals, transmural blood flow and its distribution over the subendocardial and subepicardial layers were not different from baseline, both
}

at 15 and 60 minutes of the recovery period (not shown). There were also no changes in the perfusion of the myocardium outside the distribution area of the LADCA (not shown).

\section{Oxygen consumption of the myocardium perfused by the left anterior descending coronary artery}

Fifteen minutes after the last of 15 sequences of occlusion and reperfusion, myocardial oxygen consumption $\left(\mathrm{MVO}_{2}\right)$ of the LADCA-perfused myocardiurn was reduced from $486 \pm 31 \mu \mathrm{mol} / \mathrm{min} / \mathrm{g}$ to $326 \pm 44 \mu \mathrm{mol} /$ $\mathrm{min} / \mathrm{g}(\mathrm{p}<0.05)$ and did not fully recover during the following 60 minutes of reperfusion $(394 \pm 20 \mu \mathrm{mol} /$ $\mathrm{min} / \mathrm{g}, \mathrm{p}<0.05)$. Trimetazidine did not modify this pattern, as $\mathrm{MVO}_{2}$ had decreased from $467 \pm 48 \mu \mathrm{mol} /$ $\mathrm{min} / \mathrm{g}$ to $362 \pm 86 \mu \mathrm{mol} / \mathrm{min} / \mathrm{g}(\mathrm{p}<0.05)$ at $15 \mathrm{~min}-$ utes of reperfusion in the treated animals and was only $372 \pm 27 \mu \mathrm{mol} / \mathrm{min} / \mathrm{g}$ after 60 minutes of reperfusion.

\section{Myocardial high-energy phosphate levels}

In the untreated animals, myocardial ATP content after the first five occlusion-reperfusion sequences (28 $\pm 2 \mu \mathrm{mol} / \mathrm{g}$ protein) was not different from the values measured at baseline ( $28 \pm 3 \mu \mathrm{gmol} / \mathrm{g}$ protein), but during the following 10 occlusion-reperfusion sequences there was a gradual decrease to $23 \pm 2 \mu \mathrm{mol} /$ $\mathrm{g}$ protein $(\mathrm{p}<0.05)$. There was no recovery during the first 15 minutes of reperfusion $(20 \pm 2 \mu \mathrm{mol} / \mathrm{g}$ protein). In the trimetazidine-treated animals (32 \pm $2 \mu \mathrm{mol} / \mathrm{g}$ protein at baseline) a similar pattern in the changes in ATP content was observed $(29 \pm 3,26 \pm$ 3 , and $27 \pm 3 \mu \mathrm{gmol} / \mathrm{g}$ protein, at the end of the 5th and 15th occlusion-reperfusion sequence and after 15 minutes of recovery, respectively).

For both groups of animals, the total adenine nucleotide levels followed the same pattern as the ATP levels. CP levels had increased significantly $(p<0.05)$ from $37 \pm 7 \mu \mathrm{mol} / \mathrm{g}$ protein at baseline to $63 \pm 14$ $\mu \mathrm{mol} / \mathrm{g}$ protein after the 5th occlusion-reperfusion cycle in the untreated animals and from $37 \pm 4 \mu \mathrm{mol} / \mathrm{g}$ protein at baseline to $62 \pm 9 \mu \mathrm{mol} / \mathrm{g}$ protein in the treated animals $(p<0.05)$. In both groups there was a slight decline during the recovery period (to $54 \pm 9$ $\mu \mathrm{mol} / \mathrm{g}$ protein and $57 \pm 10 \mu \mathrm{mol} / \mathrm{g}$ protein in the untreated and treated animals at 15 minutes of reperfusion, respectively). The energy charge $(0.91 \pm 0.09$ at baseline for both groups) was not significantly affected during the reperfusion periods.

\section{Myocardial malondialdehyde production}

In neither the untreated animals $(0.02 \pm 0.09,0.02$ \pm 0.12 , and $0.04 \pm 0.08 \mathrm{nmol} / \mathrm{ml}$ at baseline, 2 and 10 minutes after the last occlusion, respectively) nor in the trimetazidine-treated animals $(-0.02 \pm 0.07$, $-0.08 \pm 0.02$, and $-0.05 \pm 0.08 \mathrm{nmol} / \mathrm{ml}$ at baseline, 2 and 10 minutes after the last occlusion, respectively) did we observe any significant production of MDA. 


\section{Discussion}

The model used in the present study mimicks the clinical PTCA in so far as multiple short-lasting coronary artery occlusions separated by 2 minutes of reperfusions were used. In the clinical setting the effects of PTCA on myocardial wall motion are not well defined, as the duration and number of occlusions may vary considerably. A further complicating factor may be that in experimental animals hearts are used that have not been submitted to myocardial ischemia before, while in the clinical setting the myocardium has usually experienced several episodes of myocardial ischemia and may already have an abnormal wall motion, and possibly, metabolism because of the presence of an existing chronic obstruction. Hence, phenomena such as ischemic preconditioning and hibernation may be confounding factors in clinical investigations. It is therefore not surprising that Jaski et al. [10] reported that after four to six balloon inflations, each lasting less than 1 minute, both systolic and diastolic wall motion returned to normal within 5 minutes, while Wijns et al. [11] reported an impaired diastolic function in the presence of a normal systolic function following a similar study protocol involving a larger number of occlusions. It therefore appears that diastolic function may be more sensitive to multiple short-lasting occlusions than systolic function.

In the present study, systolic segment shortening completely recovered during the first reperfusion period. As a matter of fact, there was even a slight increase in regional myocardial function and external work, which is consistent with earlier observations [18]. This may be, but is not necessarily [19], related to the hyperemic response. The aforementioned study [18] also showed that after such a short-lasting occlusion, stunning does not develop when perfusion is maintained. In the present study, myocardial stunning gradually developed during the following occlusion-reperfusion sequences and was most pronounced after reperfusion was reinstated for 15 minutes. Our observation that regional wall function completely recovered after the first occlusion, but became impaired during the following episodes of ischemia-reperfusion, appears to contradict clinical studies, which suggest, using electrocardiographic and metabolic abnormalities, that the first occlusion is the most damaging [20].

Kober et al. [9], ignoring the first occlusion, observed that electrocardiographic abnormalities were similar during the second and third occlusion in patients undergoing PTCA. When trimetazidine $(6 \mathrm{mg})$ was administered intravenously before the third occlusion, the signs of ischemia were less during balloon inflation. Using a study protocol in which demand ischemia developed rather than supply ischemia, as in the study of Kober et al. [9], Sellier et al. [1] and Dalla-Volta et al. [2] also showed less evidence of ischemia based on electrocardiographic abnormalities. The present study failed to demonstrate an effect of trimetazidine on recovery of function during reperfusion following repeated brief coronary artery occlusions. This does not necessarily contradict the observation by Kober et al. [9], considering the poor relation between functional and electrocardiographic changes [21].

Myocardial oxygen consumption (the product of coronary blood flow and difference in arterial and coronary venous oxygen content) was not affected by trimetazidine, which is in accordance with the concept that trimetazidine does not influence the hemodynamic variables determining myocardial oxygen demand, but it contrasts the suggestion that trimetazidine enhances the utilization of the available oxygen [4]. In this in vivo model, also at variance with the results found in isolated rat heart [4] and in isolated myocardial mitochondria [8], high-energy phosphates were not better preserved or restored in the presence of trimetazidine. Previously, it was shown that trimetazidine can reduce ischemia-induced acidosis in myocardium [4]. Development of acidosis is believed to contribute to the deregulation of myocardial $\mathrm{Ca}^{2+}$ homeostasis via a coupled operation of the $\mathrm{Na}^{+} / \mathrm{H}^{+}$ and the $\mathrm{Na}^{+} / \mathrm{Ca}^{2+}$ exchangers $[4,5]$. In the present investigation we did not study any variable reflecting tissue acidosis or $\mathrm{Ca}^{2+}$ overload, and a possible occurrence of a beneficial effect of trimetazidine on tissue acidosis or $\mathrm{Ca}^{2+}$ overload can therefore not be excluded.

MDA is one of the end products of the reaction of endogenously generated free radicals with membrane polyunsaturated fatty acids, but its formation in the myocardium could not be consistently demonstrated in the coronary effluent during the repetitive occlusion-reperfusion periods in the present study. This could be due to the short duration of the occlusions ( 2 minutes), as we have demonstrated previously that MDA production occurred in anesthetized pigs that were subjected to 5 -minute coronary artery occlusions [16]. On the other hand, there are two studies that showed trimetazidine attenuated oxygen free radical generation during ischemia-reperfusion $[22,23]$. It should be noted that in these studies the most convincing evidence for free radical generation and an inhibitory effect of trimetazidine on this harmful process was obtained using spin-trapping agents such as Ntert-butyl alpha phenylnitrone and electron paramagnetic resonance spectroscopy (ESR) in liquid nitrogen frozen myocardial biopsies. In one study the changes in the myocardial homogenate MDA content corresponded with the changes in ESR spectra [23]. In the present study, we determined MDA concentrations only in arterial and coronary venous blood, and no spin-trapping agents for detecting the earliest products during oxygen free radical generation were used. We can therefore not make a definite statement concerning the generation of oxygen free radicals in our study. Nevertheless, the impairment of regional wall function during reperfusion, which may be a result 
of oxygen-free radical induced damage [12], was not affected by trimetazidine in this particular model of ischemia and reperfusion.

The question may arise whether the lack of effect of trimetazidine is due to the experimental design, the choice of the experimental animal, the dose or route of the drug, or a combination of these factors. The lack of any significant effect of trimetazidine on systemic hemodynamic variables is consistent with earlier observations using intravenous doses. It is unlikely that the intracoronary dose used in this study was too low, considering the intravenous dose used in the study by Kober et al. [9]. It is also unlikely that the duration of the administration of trimetazidine was the cause for the lack of effect on regional wall function, as no improved recovery was seen when the duration of trimetazidine administration was extended until the end of the 120-minute recovery period (unpublished observations in five animals).

In conclusion, trimetazidine in this in vivo model did not affect hemodynamic, metabolic, and functional responses to 15 repetitive short-lasting occlusions.

\section{Acknowledgments}

This study was supported by a grant from I.R.I.S. (Courbevoie, France). The authors also gratefully acknowledge the skilled assistance of Miss Nathalie Beguin during the execution of the experiments.

\section{References}

1. Sellier P, Harpey C, Corona PP, Andouin P, Ourbak P. Ergometric parameters in effort angina. Cardiovasc Drugs Ther 1990;4:820-821.

2. Dalla-Volta S, Maraglino G, Della-Valentina $P$, Viena $P$, Desideri A. Comparison of trimetazidine with nifedipine in effort angina: A double-blind, crossover study. Cardiovasc Drugs Ther 1990;4:853-860.

3. Timour Q, Harpey C, Durr F, Faucon G. Is the antianginal action of trimetazidine independent of hemodynamic changes? Cardiovase Drugs Ther 1991;5:1043-1044.

4. Lavanchy N, Martin J, Rossi A. Anti-ischemic effects of trimetazidine: ${ }^{31} \mathrm{P}-\mathrm{NMR}$ spectroscopy in the isolated rat heart. Arch Int Pharmacodyn Ther 1987;286(Suppl 1): 97110.

5. Renaud JF. Internal $\mathrm{pH}, \mathrm{Na}^{+}$, and $\mathrm{Ca}^{2+}$ regulation by trimetazidine during cardiac cell acidosis. Cardiovasc Dmigs Ther 1988;1:677-686.

6. Hugtenburg JG, Jap TJW, Mathy MJ, et al. Cardioprotective effect of trimetazidine and nifedipine in guinea-pig hearts subjected to ischaemia. Arch Int Pharmacodyn 1989;300:186-208.

7. Maridonneau-Parini I, Harpey C. Effect of trimetazidine on membrane damage induced by oxygen free radicals in human red cells. Br J Pharmacol 1985;20:148-151.

8. Guarnieri C, Muscari C. Beneficial effects of trimetazidine on mitochondrial function and superoxide production in the cardiac muscle of monocrotaline-treated rats. Biochem Pharmacol 1988;37:4685-4688.
9. Kober G, Buck T. Myocardial protection during PTCA: Effects of trimetazidine. Eur Heart $J$ 1992;13:1109-1115.

10. Jaski BE, Serruys PW, Ten Katen H, Meij S. Epicardial wall motion and left ventricular function during coronary graft angioplasty in humans. $J$ Am Coll Cardiol 1985; 6:695-700.

11. Wijns W, Serruys PW, Slager CJ, et al. Effect of coronary occlusion during percutaneous transluminal angioplasty in humans on left ventricular chamber stiffness and regional diastolic pressure-radius relations. I Am Coll Cardiol $1986 ; 7: 455-463$.

12. Bolli R. Oxygen-derived free radicals and postischemic myocardial dysfunction ("stunned myocardium"). J Am Coll Cardiol 1988;12:239-249.

13. Krams R, Duncker DJ, McFalls EO, Hoogendoorn A, Verdouw PD. Dobutamine restores the reduced efficiency of energy transfer from total mechanical work to external mechanical work is stunned porcine myocardium. Cardiovasc Res, 1993;27:740-747.

14. Vinten-Johansen J, Gayheart PA, Johnston WE, Julian JS, Cordell AR. Regional function, blood flow and oxygen utilization relation in repetitively occluded-reperfused canine myocardium. Am J Physiol 1991; 261:H538-H546.

15. Sassen LMA, Bezstarosti K, Verdouw PD, Lamers JMJ. Effects of nisoldipine on recovery of coronary blood flow, sarcoplasmic reticulum function and other biochemical parameters in post-ischaemic porcine myocardium. Biochem Pharmacol 1991;41:43-51.

16. Lamers JMJ, Hartog JM, Guarnieri C, Vaona I, Verdouw PD, Koster JF. Lipid peroxidation in normoxic and ischaemic-reperfused hearts of fish oil and lard fat fed pigs. $J$ Mol Cell Cardiol 1988;20:605-615.

17. Atkinson DE. Energy charge of the adenylate pool as a regulatory parameter: Interaction with feedback modifier's. Biochemistry 1968;7:4030-4034.

18. Gaasch WH, Bernhardt SA. The effect of acute changes in coronary blood flow on left ventricular end-diastolic wall thickness-An echocardiographic study. Circulation 1977; 56:593-598.

19. Verdouw PD, Ten Cate FJ, Hugenholtz PG. Effect of nifedipine on segmental myocardial function in the anesthetized pig. Eur $J$ Pharmacol 1980;63:209-212.

20. Deutsch E, Berger M, Kussmaul WG, Hirshfeld JW, Herrmann HC, Laskey WK. Adaptation to ischemia during percutaneous transluminal coronary angioplasty. Circulation 1990;82:2044-2051.

21. Temporelli PL, Gianuzzi P, Gattone M, et al. Clinical relevance of ST segment changes during exercise in patients with anterior myocardial infarction. Eur Heart $J$ 1992; 13:403.

22. Maupoil V, Rochette L, Tabard A, Clauser P, Harpey C. Direct measurement of free radical generation in isolated rat heart by electron paramagnetic resonance spectroscopy: Effect of trimetazidine. In: Emerit I, Packer L, Auclair C, eds. Antioxidants in Therapy and Preventive Medicine. New York: Plenum Press, 1990:373-376.

23. Charlon V, Boucher F, Clauser P, et al. Effect of a 5 day trimetazidine pretreatment in a model of ischernic and reperfused isolated rat heart: Spin trapping experiments. In: Emerit I, Packer L, Auclair C, eds. Antioxidants in Therapy and Preventive Medicine. New York: Plenum Press, 1990:377-382. 